\title{
OPEN A 400-Gb/s WDM-PAM4 OWC system through the free-space transmission with a water-air-water link
}

\author{
Hai-Han Lu ${ }^{1 凶}$, Chung-Yi Li ${ }^{2}$, Xu-Hong Huang ${ }^{3}$, Poh-Suan Chang ${ }^{1}$, Yu-Ting Chen ${ }^{1}$, Yan-Yu Lin ${ }^{1}$, \\ Chen-Xuan Liu' ${ }^{1}$ \& Ting Ko ${ }^{1}$
}

A 400-Gb/s wavelength-division-multiplexing (WDM) four-level pulse amplitude modulation (PAM4) optical wireless communication (OWC) system through a 200-m free-space transmission with either an 8.8-m piped water-air-piped water link or a $6.5-\mathrm{m}$ turbid water-air-turbid water link is successfully constructed. Incorporating PAM4 modulation with an 8-wavelength WDM scheme greatly increases the total transmission rate of the WDM-PAM4 OWC system to $400 \mathrm{~Gb} / \mathrm{s}(50 \mathrm{~Gb} / \mathrm{s} / \lambda \times 8 \lambda \mathrm{s})$. By adopting doublet lenses in free-space transmission, a laser beam reducer/expander and a reflective spatial light modulator (SLM) with an angle expander through the water-air-water link, good bit error rate performance and acceptable PAM4 eye diagrams are obtained. Using a reflective SLM with an angle expander not only adaptively adjusts the laser beam, but also effectively solves the oceanic engineering problems. This demonstrates WDM-PAM4 OWC system outperforms existing OWC systems through the free-space transmission with an air-water-air link because it can solve the practical engineering problems in actual oceanic environments.

Optical wireless communication (OWC) is a form of optical communication using laser beam or light-emitting diode light to deliver optical signals in an unguided environment. Free-space optical (FSO) communication is a type of OWC that transmits optical signals via a laser beam in free-space. FSO has received extensive attention in research on the problem of high-speed free-space transmissions ${ }^{1-5}$. Underwater wireless laser transmission (UWLT) system is another type of OWC that transmits optical signals via a laser beam through an underwater link. UWLT has attracted widespread attention in research on the problem of high-speed underwater links ${ }^{6-11}$. Given the characteristics of FSO communication and UWLT system, they can provide high transmission rate over a free-space transmission with an underwater link. With the rapid progress of FSO communication and UWLT system, constructing a high-speed FSO-UWLT convergence is vitally important ${ }^{12,13}$. In an actual scenario, no UWLT system passes through the air-water-air interface as the laser beam should flee or enter from the top of the water ${ }^{14,15}$. Sending a laser beam through the air-water-air interface cannot solve the problem currently being encountered in ocean engineering. A UWLT system passes through the water-air-water interface is more practical and can resolve the problem that the oceanic engineering is currently encountering. Our previous research showed a 50-Gb/s four-level pulse amplitude modulation (PAM4) UWLT system passing through a turbid water-air-turbid water link ${ }^{16}$. However, it is just a UWLT system passing through the turbid water-air-turbid water link. It cannot satisfy the demand to incorporate the free-space transmission with a water-air-water link. An OWC system through the free-space transmission with a water-air-water link is thus built to meet the high transmission rate requirement and resolve the practical engineering problem. In this research, a 400-Gb/s wavelength-division-multiplexing (WDM) PAM4 OWC system passing through a $200-\mathrm{m}$ free-space transmission with either an $8.8-\mathrm{m}$ piped water-air-piped water link or a $6.5-\mathrm{m}$ turbid water-air-turbid water link is proposed and constructed. It shows a WDM-PAM4 OWC system using an 8-wavelength system as a demonstration; each wavelength carries a $50-\mathrm{Gb} / \mathrm{s}$ PAM4 signal data stream $(50 \mathrm{~Gb} / \mathrm{s} / \lambda \times 8 \lambda \mathrm{s})$. The scenario differences between this research and our previous research ${ }^{16}$ are illustrated in Table 1. Clearly, a UWLT system through the turbid water-air-turbid water link has a lot of room for improvement when considering the incorporation of FSO

\footnotetext{
${ }^{1}$ Institute of Electro-Optical Engineering, National Taipei University of Technology, Taipei 10608, Taiwan. ${ }^{2}$ Department of Communication Engineering, National Taipei University, New Taipei City 23741, Taiwan. ${ }^{3}$ The School of Information Science and Engineering, Fujian University of Technology, Fujian 350118, China. ${ }^{\boxplus}$ email: hhlu@ntut.edu.tw
} 


\begin{tabular}{|l|l|l|l|l|}
\hline \multirow{2}{*}{ Research } & Scenario & Transmission & Transmitter & Tracking scheme \\
\cline { 2 - 5 } Our previous research & Architecture & Water-air-water link & $\begin{array}{l}\text { VCSEL with light injection and opto- } \\
\text { electronic feedback techniques }\end{array}$ & Reflective SLM \\
\hline This research & $40 \mathrm{~Gb} / \mathrm{s}$ WDM-PAM4 OWC system & $\begin{array}{l}\text { Free-space transmission with water- } \\
\text { air-water link }\end{array}$ & $\begin{array}{l}\text { (1) Eight WDM wavelengths } \\
\text { (2) R/B-light LD with two-stage light } \\
\text { injection techniques }\end{array}$ & Reflective SLM with angle expander \\
\hline
\end{tabular}

Table 1. The scenario differences between this research and our previous research.

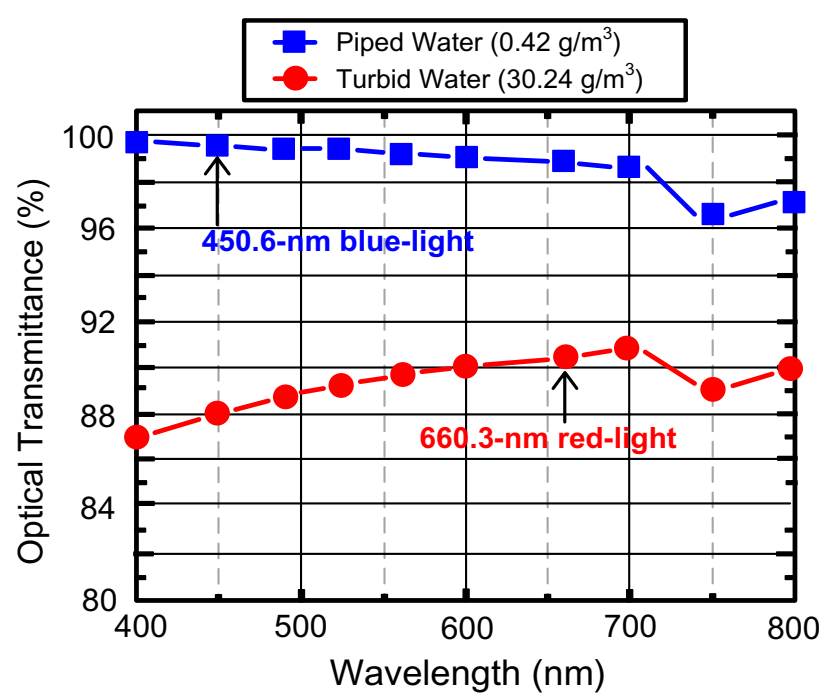

Figure 1. The optical transmittances at particle concentrations of 0.42 (piped water) and $30.24 \mathrm{~g} / \mathrm{m}^{3}$ (turbid water).

communication with the UWLT system. By utilizing a pair of doublet lenses in free-space transmission ${ }^{17,18}$, a laser beam reducer/expander and a reflective spatial light modulator (SLM) with an angle expander in water-air-water link $\mathrm{k}^{19-21}$, good low bit error rate (BER) and acceptable PAM4 eye pattern are obtained over a 200-m free-space transmission with either an 8.8-m piped water-air-piped water link or a 6.5-m turbid water-air-turbid water link. Because the light at $1550 \mathrm{~nm}$ is less attenuated by the atmosphere than visible light ${ }^{22,23}$ and because an erbium-doped fiber amplifier (EDFA) can only magnify optical signals in the $1550 \mathrm{~nm}$ region, the wavelengths from 1535.82 to $1541.35 \mathrm{~nm}$ are selected in the FSO link of the OWC system. By using the low absorption of the piped water at the blue-light (B-light) wavelength ${ }^{24,25}$, a 450.6-nm B-light laser diode (LD) employing two-stage light injection technique is adopted through the piped water-air-piped water link. Moreover, by using the low attenuation of the turbid water at the red-light (R-light) wavelength ${ }^{26,27}$, a $660.3-\mathrm{nm}$ R-light LD employing twostage light injection technique is adopted through the turbid water-air-turbid water link.

One of the main challenges of the water-air-water link is the movement of the laser beam (lateral/vertical movement) produced by the water flow ${ }^{28,29}$. In actual situations, the movement of the laser beam due to water flow will cause the link to be unstable and lead to performance degradation. Therefore, laser beam tracking through the water-air-water interface is crucial in a UWLT system. A reflective SLM with an angle expander is thus used as a laser beam tracking scheme to reduce the movement of the laser beam caused by the water flow. An SLM with an angle expander not only operates as a flexible mirror to adaptively reflect the laser beam and maintain a reliable water-air-water link, but also solves the key problem currently being encountered by UWLT systems.

A WDM-PAM4 OWC system with an accumulative transmission rate of $400 \mathrm{~Gb} / \mathrm{s}$ over $200-\mathrm{m}$ free-space transmission with 8.8 -m piped water-air-piped water link/6.5-m turbid water-air-turbid water link is successfully built. With SLM and angle expander-based beam tracking scheme, the laser beam can be controlled to mitigate its movement due to water flow, and the practical engineering problem can be solved to establish a stable OWC system. Compared with previous OWC systems through the free-space transmission with an air-water-air $\operatorname{link}^{6-11}$, it presents an excellent system with the advantages of high accumulative transmission rate, long-distance optical wireless transmission, and high reliability.

\section{Results}

The optical transmittances at different particle concentrations. The optical transmittances at particle concentrations of 0.42 (piped water) and $30.24 \mathrm{~g} / \mathrm{m}^{3}$ (turbid water) are presented in Fig. 1. At a particle concentration of $0.42 \mathrm{~g} / \mathrm{m}^{3}$ (piped water), the optical transmittance of B-light with a wavelength of $450.6 \mathrm{~nm}$ is higher than that of R-light with a wavelength of $660.3 \mathrm{~nm}$. Thus, B-light outperforms R-light through the piped 

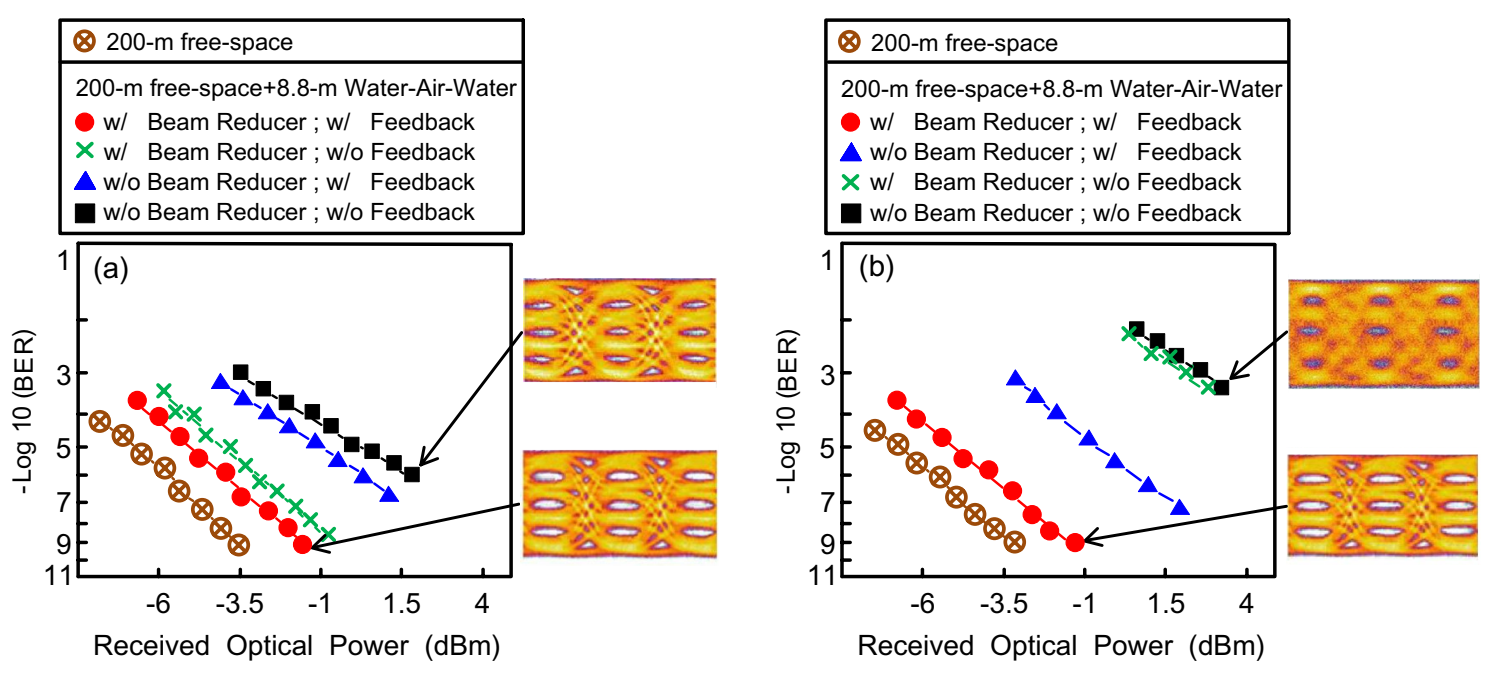

Figure 2. (a) BER performances of the $400 \mathrm{~Gb} / \mathrm{s}$ WDM-PAM4 OWC system through $200 \mathrm{~m}$ free-space transmission and through $200 \mathrm{~m}$ free-space transmission with $8.8 \mathrm{~m}$ piped water-air-piped water link, at the beginning (within the first $5 \mathrm{~min}$ ) and at a filtered wavelength of $\lambda_{1}$. (b) BER performances of $400 \mathrm{~Gb} / \mathrm{s}$ WDMPAM4 OWC system under different scenarios, after an hour and at a filtered wavelength of $\lambda_{7}$.

water-air-piped water interface. At a $30.24 \mathrm{~g} / \mathrm{m}^{3}$ (turbid water) particle concentration, the optical transmittance of R-light with a wavelength of $660.3 \mathrm{~nm}$ is higher than that of B-light with a wavelength of $450.6 \mathrm{~nm}$. Thus, R-light outperforms B-light through the turbid water-air-turbid water interface. In a piped water link, R-light suffers from greater absorption, and its advantage in terms of less scattering is not obvious. In a turbid water link, B-light suffers from greater scattering, and its advantage in terms of less absorption is not obvious. In conclusion, B-light is better for a piped water-air-piped water interface, whereas R-light is better for a turbid water-air-turbid water interface ${ }^{30,31}$.

BER performances of $400 \mathrm{~Gb} / \mathrm{s}$ WDM-PAM4 OWC system through $200 \mathrm{~m}$ free-space transmission and through $200 \mathrm{~m}$ free-space transmission with $8.8 \mathrm{~m}$ piped water-air-piped water link, and eye diagrams of $50 \mathrm{~Gb} / \mathrm{s}$ PAM4 signal in different states. Figure 2a shows the BER performances of the $400 \mathrm{~Gb} / \mathrm{s}$ WDM-PAM4 OWC system through $200 \mathrm{~m}$ free-space transmission and through $200 \mathrm{~m}$ free-space transmission with $8.8 \mathrm{~m}$ piped water-air-piped water link, at the beginning (within the first $5 \mathrm{~min}$ ) and at a filtered wavelength of $\lambda_{1}$. As BER reaches $10^{-9}$, a power penalty of approximately $2 \mathrm{~dB}$ exists between the condition through $200 \mathrm{~m}$ free-space transmission and that through $200 \mathrm{~m}$ free-space transmission with $8.8 \mathrm{~m}$ piped water-air-piped water link. This $2-\mathrm{dB}$ power penalty is chiefly ascribed to the atmospheric attenuation from the $6.28 \mathrm{~m}$ free-space transmission and the absorption from the $2.52 \mathrm{~m}$ piped water link. Moreover, in the absence of a feedback signal (with laser beam reducer), BER increases slightly from $10^{-9}$ to $6 \times 10^{-9}$. At the beginning, the movement of laser beam caused by the water flow is very small. Therefore, in the absence of a feedback signal, BER increases slightly. Furthermore, in the absence of a laser beam reducer (with feedback signal), BER increases to $3 \times 10^{-7}$. In the absence of a laser beam reducer and feedback signal, BER further increases to $10^{-6}$. Using a laser beam reducer, BER reaches an order of $10^{-9}$. Without using a laser beam reducer, BER increases to an order of $10^{-7} \sim 10^{-6}$. At the beginning, a laser beam reducer is an important factor in the UWLT system through the piped water-air-piped water link. Regarding PAM4 eye diagrams, open eye diagrams are observed in the presence of a laser beam reducer and feedback signal. In the absence of a laser beam reducer and feedback signal, a more or less clear eye diagram is obtained.

Figure $2 \mathrm{~b}$ displays the BER performances of the $400 \mathrm{~Gb} / \mathrm{s}$ WDM-PAM4 OWC system under different scenarios, after an hour and at a filtered wavelength of $\lambda_{7}$. At a value of $10^{-9} \mathrm{BER}$, a power penalty of about $2 \mathrm{~dB}$ occurs between the scenario through $200 \mathrm{~m}$ free-space transmission and that through $200 \mathrm{~m}$ free-space transmission with $8.8 \mathrm{~m}$ piped water-air-piped water link. The 2-dB power penalty results from the atmospheric attenuation because of the $6.28 \mathrm{~m}$ free-space transmission and the absorption because of the $2.52 \mathrm{~m}$ piped water link. Furthermore, in the absence of a laser beam reducer (with feedback signal), BER increases to $5.2 \times 10^{-8}$. Moreover, in the absence of a feedback signal (with or without laser beam reducer), BER significantly increases to $4.3 \times 10^{-4}$. Over time (after an hour), the movement of laser beam produced by the water flow is quite large. However, the feedback signal supplied in an electrical controller can arbitrarily adapt the laser beam and thereby mitigate the movement of laser beam. Over time, a feedback signal is the key factor in the UWLT system through the piped water-air-piped water link. Figure $2 \mathrm{~b}$ also shows the eye diagrams of the $50 \mathrm{~Gb} / \mathrm{s}$ PAM4 signal in different states. In the presence of a laser beam reducer and feedback signal, open eye diagrams are attained. In the absence of a laser beam reducer and feedback signal, blurred eye diagrams are acquired.

BER performances of $400 \mathrm{~Gb} / \mathrm{s}$ WDM-PAM4 OWC system through $200 \mathrm{~m}$ free-space transmission and through $200 \mathrm{~m}$ free-space transmission with $6.5 \mathrm{~m}$ turbid water-air-turbid water link, 

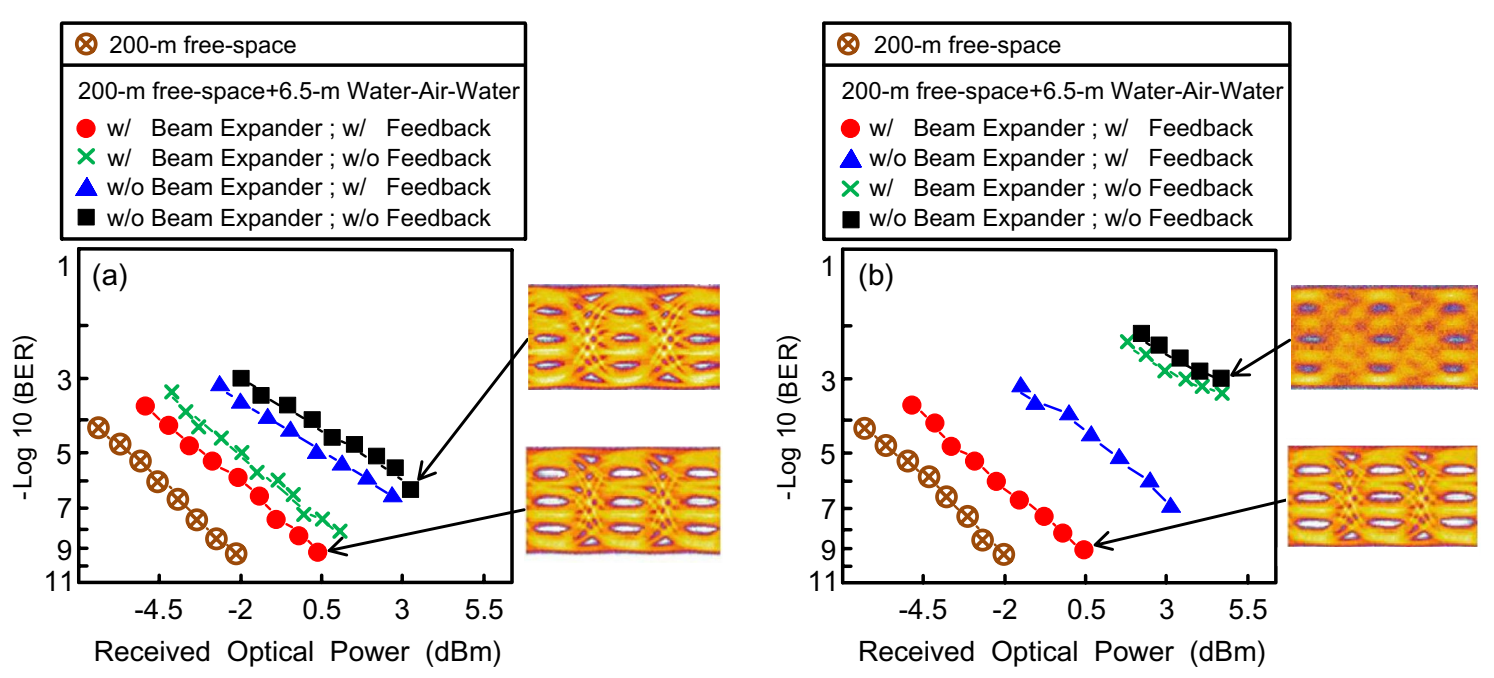

Figure 3. (a) At the beginning (within the first $5 \mathrm{~min}$ ) and at a filtered wavelength of $\lambda_{2}$, the BER performances of the $400 \mathrm{~Gb} / \mathrm{s}$ WDM-PAM4 OWC system through $200 \mathrm{~m}$ free-space transmission and through $200 \mathrm{~m}$ freespace transmission with $6.5 \mathrm{~m}$ turbid water-air-turbid water link. (b) After an hour and at a filtered wavelength of $\lambda_{8}$, the BER performances of the $400 \mathrm{~Gb} / \mathrm{s}$ WDM-PAM4 OWC system under different conditions.

and eye diagrams of $50 \mathrm{~Gb} / \mathrm{s}$ PAM4 signal in different conditions. At the beginning (within the first $5 \mathrm{~min}$ ) and at a filtered wavelength of $\lambda_{2}$, the BER performances of the $400 \mathrm{~Gb} / \mathrm{s}$ WDM-PAM4 OWC system through $200 \mathrm{~m}$ free-space transmission and through $200 \mathrm{~m}$ free-space transmission with $6.5 \mathrm{~m}$ turbid water-airturbid water link is shown in Fig. 3a. At a $10^{-9} \mathrm{BER}$ value, a power penalty of around $2.5 \mathrm{~dB}$ exists between the state over $200 \mathrm{~m}$ free-space transmission and that over $200 \mathrm{~m}$ free-space transmission with $6.5 \mathrm{~m}$ turbid waterair-turbid water link. Because scattering is the dominant factor in a turbid water link, this $2.5-\mathrm{dB}$ power penalty mainly arises from the atmospheric attenuation due to $5 \mathrm{~m}$ free-space transmission and the scattering effect due to $1.5 \mathrm{~m}$ turbid water link. In addition, in the absence of a feedback signal (with laser beam expander), BER somewhat increases from $10^{-9}$ to $9.2 \times 10^{-9}$. At the beginning, the movement of laser beam induced by the water flow is very small. The feedback signal thereby affords a slight improvement in BER performance. Moreover, in the absence of a laser beam expander (with feedback signal), BER increases to $6.5 \times 10^{-7}$. In the absence of a laser beam expander and feedback signal, BER further increases to $3 \times 10^{-6}$. At the beginning, the laser beam expander is the crucial factor in the UWLT system through the turbid water-air-turbid water link. Concerning PAM4 eye diagrams, open eye diagrams are acquired in the condition with a laser beam expander and feedback signal. In the condition without a laser beam expander and feedback signal, a somewhat clear eye pattern is attained.

The BER performances of the $400 \mathrm{~Gb} / \mathrm{s}$ WDM-PAM 4 OWC system after an hour and at a filtered wavelength of $\lambda_{8}$ under different conditions are presented in Fig. 3b. As BER is $10^{-9}$, a $2.5-\mathrm{dB}$ power penalty emerges between the condition over $200 \mathrm{~m}$ free-space transmission and that over $200 \mathrm{~m}$ free-space transmission with $6.5 \mathrm{~m}$ turbid water-air-turbid water link. This $2.5-\mathrm{dB}$ power penalty is mostly attributed to the atmospheric attenuation from the $5 \mathrm{~m}$ free-space transmission and the scattering effect from the $1.5 \mathrm{~m}$ turbid water link. Moreover, in the condition with a feedback signal but without a laser beam expander, BER performance worsens to $8.5 \times 10^{-8}$. In addition, in the condition without a feedback signal (with or without a laser beam expander), BER performance critically worsens to $8 \times 10^{-4}$. Over time, the feedback signal is the influential factor in the UWLT system through the turbid water-air-turbid water link. Figure $3 \mathrm{~b}$ also exhibits the $50 \mathrm{~Gb} / \mathrm{s}$ PAM4 signal's eye diagrams under different conditions. In the condition with a laser beam expander and feedback signal, open eye diagrams are acquired. Whereas in the condition without a laser beam expander and feedback signal, the eye diagrams are almost closed.

\section{Discussion}

For a UWLT system passing through the piped water-air-piped water link, the main factor is absorption, and the low scattering coefficient prevents the laser beam from diverging. Using a laser beam reducer to decrease the beam size will improve the performance of the UWLT system passing through the piped water-air-piped water link because the pipe water absorbs less laser light ${ }^{32}$. As for the UWLT system passing through the turbid water-air-turbid water interface, the avalanche photodiode (APD) with a trans-impedance amplifier (TIA) receiver will receive a large amount of scattered light when using a laser beam expander to increase the beam size $^{33,34}$. Employing a laser beam expander to expand the beam size, the performance of the UWLT system through the turbid water-air-turbid water interface is improved. Since that the beam divergence is inversely proportional to the beam size, a reduced beam divergence occurs with a laser beam expander. A larger beam size that follows a smaller beam divergence contributes more scattered light received by the APD with a TIA receiver, and thus results in better performance. Nevertheless, a larger beam size accompanies a larger absorption. For a UWLT system passing through the turbid water-air-turbid water interface, given that the ratio of absorbed light is small, a smaller beam divergence with a larger beam size brings on a smaller amount of light 
(a)

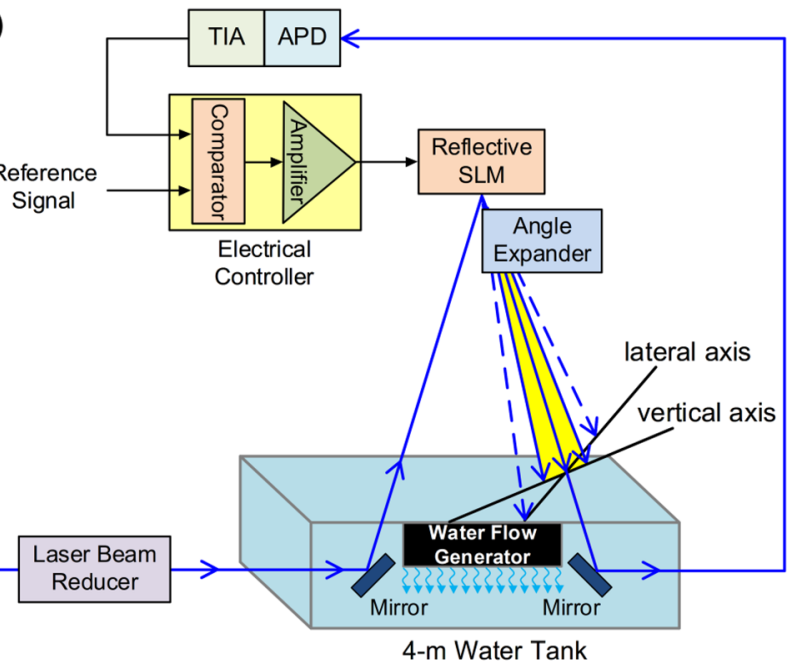

(b)

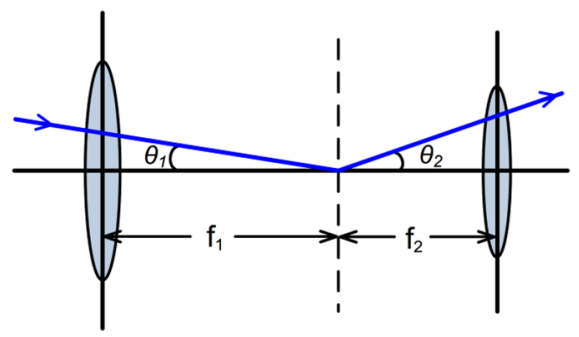

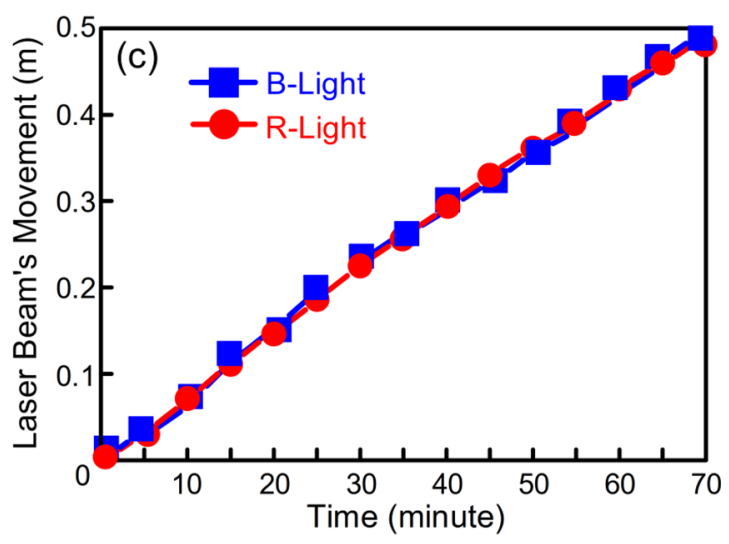

Figure 4. (a) The reflective SLM with an angle expander for developing a UWLT system across the water-airwater interface and mitigating link interruption caused by the movement of the laser beam (lateral or vertical movement). (b) The angle expander based on an afocal system, which comprises two convex lenses with $f_{1}$ $(50 \mathrm{~mm})$ and $f_{2}(25.4 \mathrm{~mm})$ focal lengths. (c) The movement of the laser beam (lateral movement) over $70 \mathrm{~min}$.

absorbed by the turbid water. Consequently, the advantage of large beam size is attained. A laser beam reducer/ expander is an important factor in improving the performance of the UWLT system through the piped/turbid water-air-piped/turbid water link.

The reflective SLM with an angle expander for developing a UWLT system across the water-air-water interface and mitigating link instability caused by the movement of the laser beam (lateral or vertical movement) is shown in Fig. 4a. Water flow brings on the movement of the laser beam, causing the APD with a TIA receiver to receive less light, thereby generating a low-level signal. The electrical controller receives the reference signal and the low-level signal, compares them, generates an amplified output voltage to make the liquid crystal inside the SLM work, and adaptively adjusts the laser beam. Figure $4 \mathrm{~b}$ illustrates the angle expander based on an afocal system, which comprises two convex lenses with $f_{1}(50 \mathrm{~mm})$ and $f_{2}(25.4 \mathrm{~mm})$ focal length $\mathrm{s}^{35}$. The distance of two convex lenses is equal to the sum of the focal lengths $\left(f_{1}+f_{2}\right)$. The function of the angle expander is to magnify the output beam angle $\left(\theta_{2}\right)$ :

$$
\theta_{2}=\theta_{1} \cdot\left(\frac{f_{1}}{f_{2}}\right)
$$

where $\theta_{1}$ is the input beam angle, and $f_{1} / f_{2}(50 \mathrm{~mm} / 25.4 \mathrm{~mm} \sim 2)$ is the focal length ratio (magnification factor). Clearly, output beam angle increases with the increase in focal length ratio. After passing through an angle expander, a reflective SLM with $\pm 5^{\circ}$ diffraction angle is expanded into $\mathrm{a} \pm 10^{\circ}$ diffraction angle. Within a beam tracking angle of $\pm 10^{\circ}$, the laser beam can have a larger lateral/vertical beam tracking range to make up for the BER decline produced by the movement of the laser beam. Given that the reflective SLM with an angle expander has a diffraction angle of $\pm 10^{\circ}$, the lateral/vertical beam tracking range (TR) in the UWLT system through the piped water-air-piped water interface can be extended from $\pm 0.29 \mathrm{~m}$ to $\pm 0.58 \mathrm{~m}$ :

$$
T R=3.4 \times\left(5 \times \frac{\pi}{180}\right)=0.29(\mathrm{~m})
$$




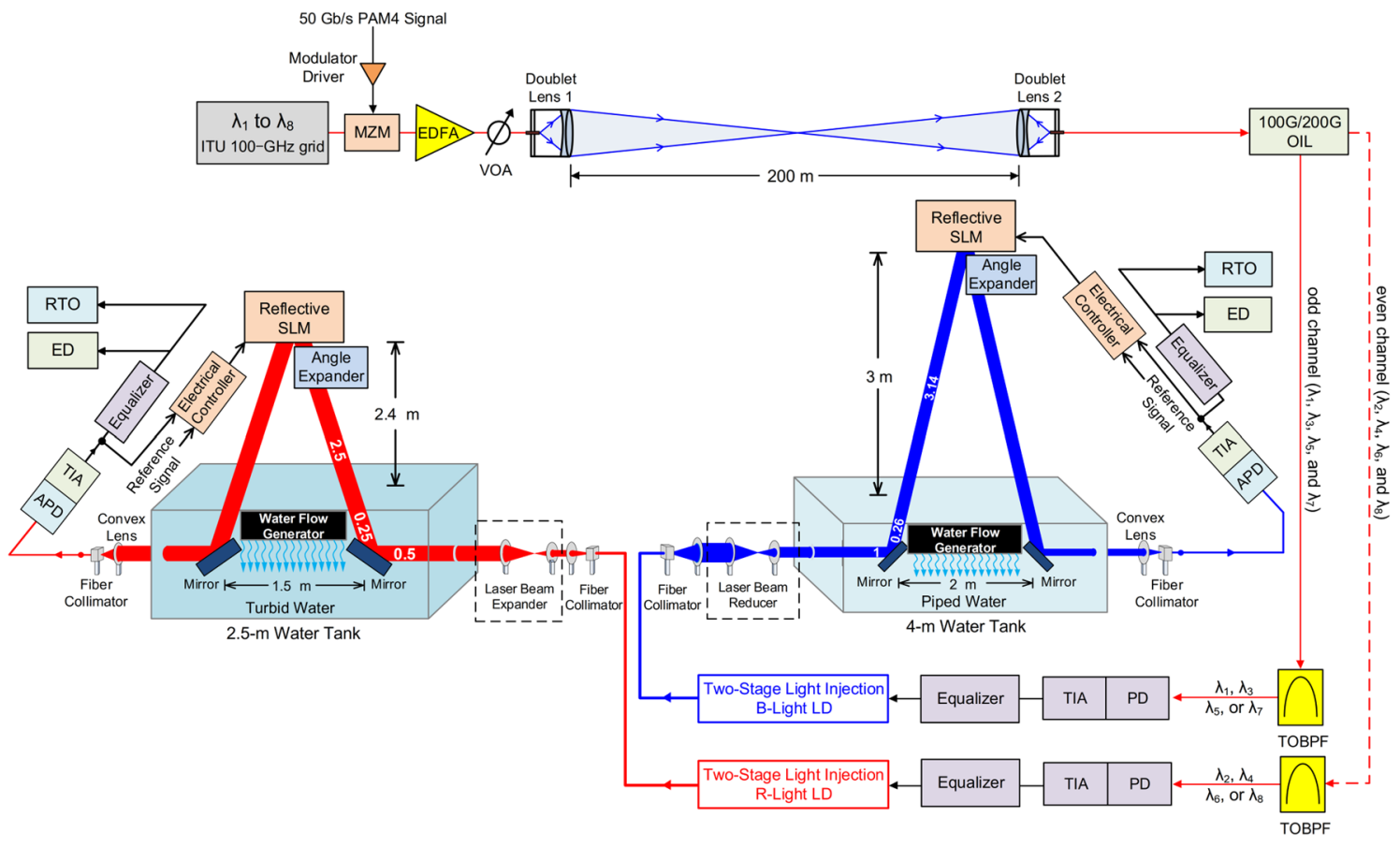

Figure 5. The architecture of the $400 \mathrm{~Gb} / \mathrm{s}$ WDM-PAM4 OWC system through $200 \mathrm{~m}$ free-space transmission with either $8.8 \mathrm{~m}$ piped water-air-piped water link or $6.5 \mathrm{~m}$ turbid water-air-turbid water link.

$$
T R=3.4 \times\left(10 \times \frac{\pi}{180}\right)=0.58(\mathrm{~m}) .
$$

Meanwhile, the lateral/vertical beam tracking range in the UWLT system through the turbid water-air-turbid water link can be extended from $\pm 0.24 \mathrm{~m}$ to $\pm 0.48 \mathrm{~m}$ :

$$
\begin{gathered}
T R=2.75 \times\left(5 \times \frac{\pi}{180}\right)=0.24(\mathrm{~m}) \\
T R=2.75 \times\left(10 \times \frac{\pi}{180}\right)=0.48(\mathrm{~m}) .
\end{gathered}
$$

The values of $\pm 0.58 \mathrm{~m}$ and $\pm 0.48 \mathrm{~m}$, taken from Eqs. (3) and (5), indicate the maximum lateral/vertical beam tracking ranges. In the lateral/vertical beam tracking range, the laser beam can be arbitrarily adapted to mitigate the BER deterioration caused by the flow of water.

The movement of the laser beam (lateral movement) over $70 \mathrm{~min}$ is presented in Fig. 4c. Obviously, the movement of laser beam increases with the increase in time. In the first $5 \mathrm{~min}$, the movement of laser beam caused by the water flow is very small. After an hour, nevertheless, the movement of laser beam produced by the water flow is quite large. Although the average speed of the water flow in the first $5 \mathrm{~min}$ and after an hour is nearly the same (approximately $1.5 \mathrm{~m} / \mathrm{s}$ ), however, the movement of laser beam due to water flow will accumulate as time increases. For example, in the first $5 \mathrm{~min}$, the movement of laser beam caused by the water flow is $0.03 \mathrm{~m}$. In the first $10 \mathrm{~min}$, the movement of laser beam produced by the water flow moves from 0.03 to $0.07 \mathrm{~m}$, instead of from 0 to $0.04 \mathrm{~m}$. Therefore, the longer the time, the larger the movement of the laser beam.

\section{Methods}

Architecture of the $400 \mathrm{~Gb} / \mathrm{s}$ WDM-PAM4 OWC system through a 200-m free-space transmission with either an 8.8-m piped water-air-piped water link or a $6.5-\mathrm{m}$ turbid water-air-turbid water link. The architecture of the $400 \mathrm{~Gb} / \mathrm{s}$ WDM-PAM4 OWC system through a 200-m free-space transmission with either an 8.8-m piped water-air-piped water link or a 6.5-m turbid water-air-turbid water link is presented in Fig. 5. Eight WDM wavelengths from 1535.82 to $1541.35 \mathrm{~nm}$ with $100 \mathrm{GHz}$ spacing are used as optical carriers. These eight optical carriers from $\lambda_{1}$ to $\lambda_{8}$ are fed into a Mach-Zehnder modulator that is modulated by a 50-Gb/s PAM4 signal generated from the PAM4 signal generator. Then, the optical signals are amplified by an EDFA with an output power of $16 \mathrm{dBm}$ at an input power of $0 \mathrm{dBm}$, optimally reduced by a variable optical attenuator, and transmitted by a couple of doublet lens over $200 \mathrm{~m}$ free-space transmission. The transmitted optical signals are supplied in a $100 \mathrm{GHz} / 200 \mathrm{GHz}$ optical inter-leaver (OIL) to separate odd (even) wavelengths. The outputs of the OIL are sent to different tunable optical band-pass filters (TOBPFs) with $0.44 \mathrm{~nm} 3-\mathrm{dB}$ bandwidth and $500 \mathrm{~dB} / \mathrm{nm}$ filter slope to filter the desired optical wavelengths. The demultiplexing scheme is composed of one OIL and two TOBPFs. The function of the demultiplexing scheme is to distinguish 

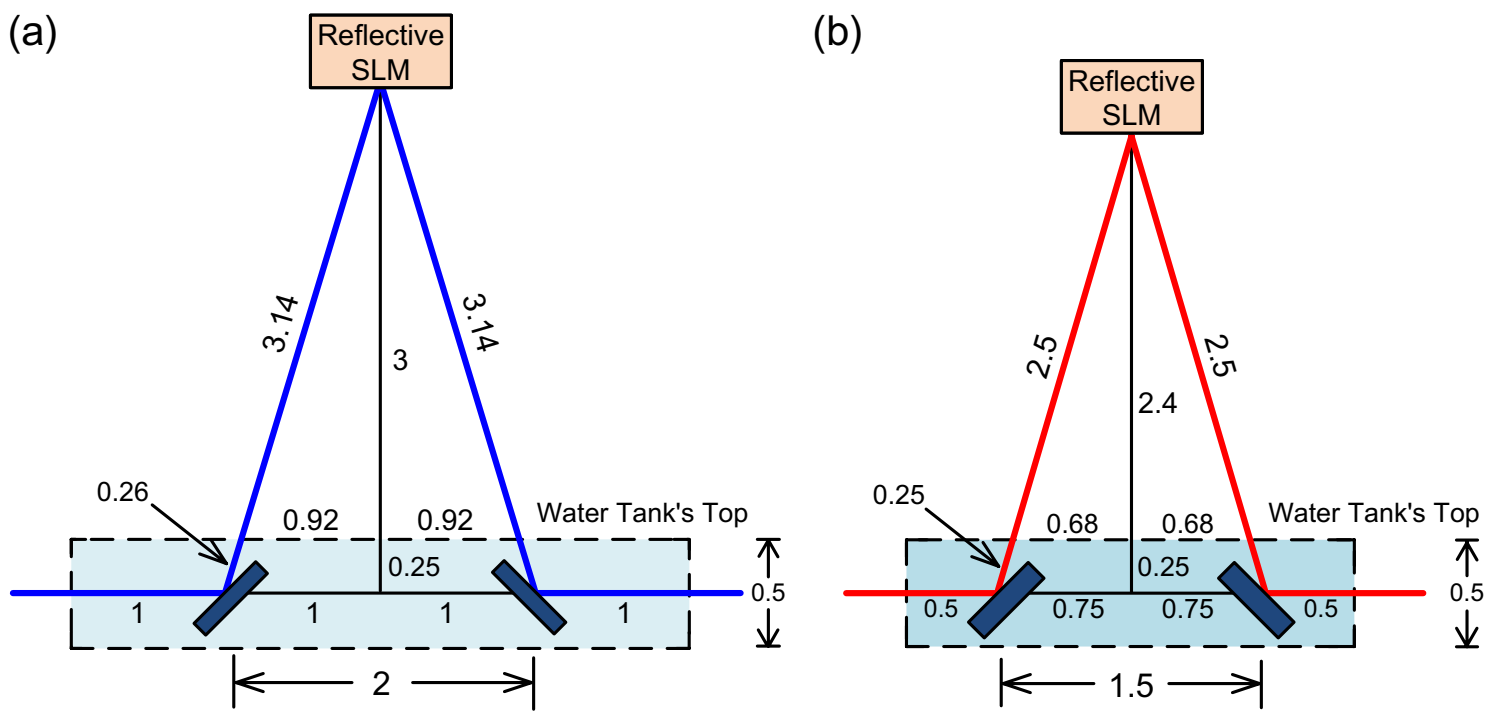

Figure 6. (a) An $8.8-\mathrm{m}(1 \times 2+0.26 \times 2+3.14 \times 2)$ piped water-air-piped water link. (b) A $6.5-\mathrm{m}$ $(0.5 \times 2+0.25 \times 2+2.5 \times 2)$ turbid water-air-turbid water link.

each optical wavelength from the output of the demultiplexing scheme. Next, a 22-GHz PD with a TIA receiver, with $4.5 \mathrm{~V}$ PD reverse bias voltage and $0.91 \mathrm{~A} / \mathrm{W}$ responsivity at $1540 \mathrm{~nm}$, receives and enhances the filtered optical signal. If eight optical wavelengths are distinguished at the same time, then two $1 \times 4 \mathrm{WDM}$ demultiplexers (or one $1 \times 8 \mathrm{WDM}$ demultiplexer) and eight PDs with TIA receivers are required to separate, receive, and enhance each optical wavelength. However, there will be crosstalk that arises from the incomplete isolation of the adjacent channels. Such crosstalk will cause performance degradation. Moreover, these eight PDs with TIA receivers will increase the cost of WDM-PAM4 OWC systems. For a real implementation of WDM-PAM4 OWC system, it is necessary to develop a low-cost demultiplexing scheme. An equalizer is used to equalize the boosted $50 \mathrm{~Gb} / \mathrm{s}$ PAM4 signal. After equalization, the $50 \mathrm{~Gb} / \mathrm{s}$ PAM4 signal is fed into a 450.6-nm B-light/660.3-nm R-light LD based on a two-stage light injection technique ${ }^{36,37}$. The 450.6 -nm B-light LD has an optical output power of $1 \mathrm{dBm}$ (30 mA operating current) to $6 \mathrm{dBm}$ (42 mA operating current), and the 660.3-nm R-light LD has an optical output power of $3.5 \mathrm{dBm}$ ( $42 \mathrm{~mA}$ operating current) to $8 \mathrm{dBm}$ ( $55 \mathrm{~mA}$ operating current). The laser beam emitted from the 450.6-nm B-light LD employing two-stage light injection technique is inputted into a laser beam reducer to reduce the laser beam's diameter from $2.2 \mathrm{~mm}$ to $1.1 \mathrm{~mm}$. The reduced laser beam is transmitted through a water tank with a size of $4 \mathrm{~m} \times 0.5 \mathrm{~m} \times 0.5 \mathrm{~m}$ (length $\times$ width $\times$ height). The water tank is filled with piped water with a particle concentration of $0.42 \mathrm{~g} / \mathrm{m}^{3}$. Two plane mirrors, with a separation distance of $2 \mathrm{~m}$, are placed in the water tank to reflect the laser beam through the piped water-air-piped water link. A reflective SLM, with $5 \mathrm{~ms}$ response time, $95 \%$ reflectivity and $\pm 5^{\circ}$ diffraction angle, is placed above the water tank to reflect the downstream laser beam adaptively. Response time is the key parameter of reflective SLM. Because the average speed of the water flow is about $1.5 \mathrm{~m} / \mathrm{sec}$, the response time $(5 \mathrm{~ms})$ of the reflective SLM can satisfy the requirement to adaptively adjust the laser beam passing through the water-air-water interface. To achieve a high reflectivity of $95 \%$, a mirror coating is put on the backplane of the reflective SLM. Subsequently, an angle expander is employed to expand the reflection angle of the downstream laser beam. Given that the distance between the reflective SLM and the top of the water tank is $3 \mathrm{~m}$, an $8.8-\mathrm{m}(1 \times 2+0.26 \times 2+3.14 \times 2)$ piped water-air-piped water link, as shown in Fig. 6a, is attained. A water flow generator with a speed of $1.5 \mathrm{~m} / \mathrm{sec}$ is utilized to simulate water flow. After reflection by the right-side plane mirror in the water tank, the laser beam is concentrated by a convex lens to guide it into a fiber collimator, and then amplified by a $25-\mathrm{GHz}$ avalanche PD (APD) with a TIA receiver with $20 \mathrm{~V}$ APD reverse bias voltage and $32 \mathrm{~A} / \mathrm{W}$ responsivity at $450.6 \mathrm{~nm}$. A part of the amplified $50 \mathrm{~Gb} / \mathrm{s}$ PAM4 signal (feedback signal) is supplied in an electrical controller to adapt the reflected laser beam. Another part of the amplified $50 \mathrm{~Gb} / \mathrm{s}$ PAM4 signal is supplied in an equalizer with a 28-Gb/s error detector (ED) to evaluate BER performances in real-time. Furthermore, a real-time oscilloscope (RTO) is utilized to seize the eye diagrams of the $50 \mathrm{~Gb} / \mathrm{s}$ PAM4 signal.

The laser beam emitted from the $660.3 \mathrm{~nm}$ R-light LD employing two-stage light injection technique is supplied in a laser beam expander to increase the laser beam's diameter from $2.2 \mathrm{~mm}$ to $4.4 \mathrm{~mm}$. The expanded laser beam is delivered across a water tank with a dimension of $2.5 \mathrm{~m} \times 0.5 \mathrm{~m} \times 0.5 \mathrm{~m}$ (length $\times$ width $\times$ height). The water tank is filled with turbid water with a particle concentration of $30.24 \mathrm{~g} / \mathrm{m}^{3}$. Two plane mirrors, with a separation distance of $1.5 \mathrm{~m}$, are placed in the water tank to reflect the laser beam across the turbid water-air-turbid water interface. A reflective SLM with an angle expander is placed above the water tank to adjust the downstream laser beam adaptively. Because the distance between the reflective SLM and the water tank's top is $2.4 \mathrm{~m}$, a $6.5-\mathrm{m}$ turbid water-air-turbid water link, as presented in Fig. 6b, is obtained. A water flow generator with a speed of $1.5 \mathrm{~m} / \mathrm{sec}$ is utilized to simulate water flow. After reflection by the left-side plane mirror in the water tank, the laser beam is focused by a convex lens to conduct it into a fiber collimator, then improved by a high-bandwidth APD with a TIA receiver with $20 \mathrm{~V}$ APD reverse bias voltage and $25 \mathrm{~A} / \mathrm{W}$ responsivity at $660.3 \mathrm{~nm}$. A portion of the improved $50 \mathrm{~Gb} / \mathrm{s}$ PAM4 signal (feedback signal) is fed into an electrical controller to attune the reflected 
laser beam adaptively. Another portion of the enhanced $50 \mathrm{~Gb} / \mathrm{s}$ PAM4 signal is fed into an equalizer with a high-sensitivity ED for real-time BER measurement. Additionally, an RTO is used to take the $50 \mathrm{~Gb} / \mathrm{s}$ PAM4 signal's eye diagrams.

Received: 16 July 2021; Accepted: 21 October 2021

Published online: 02 November 2021

\section{References}

1. Lu, H. H. et al. $800 \mathrm{~Gb} / \mathrm{s} / 200 \mathrm{~m}$ FSO link with a WDM-PAM4 scheme and SLM-based beam tracking technology. Opt. Lett. 46, 1269-1272 (2021).

2. Li, C. Y. et al. A WDM PAM4 FSO-UWOC integrated system with a channel capacity of $100 \mathrm{~Gb} / \mathrm{s}$. IEEE/OSA J. Light. Technol. 38, 1766-1776 (2020).

3. Mesleh, R. \& AL-Olaimat, A. Acousto-optical modulators for free space optical wireless communication systems. IEEE/OSA J. Opt. Commun. Netw. 10, 515-522 (2018).

4. Kaushal, H. \& Kaddoum, G. Optical communication in space: Challenges and mitigation techniques. IEEE Commun. Surv. Tut. 19, 57-96 (2017).

5. Lin, W. Y. et al. 10m/500Mbps WDM visible light communication systems. Opt. Express 20, 9919-9924 (2012).

6. Niu, W. et al. Nonlinearity mitigation based on modulus pruned look-op table for multi-bit delta-sigma 32-CAP modulation in underwater visible light communication system. IEEE Photonics J. 13, 7900712 (2021).

7. Lyu, W. C. et al. Experimental demonstration of an underwater wireless optical communication employing spread spectrum technology. Opt. Express 28, 10027-10038 (2020).

8. Hong, X., Fei, C., Zhang, G. \& He, S. Probabilistically shaped 256-QAM-OFDM transmission in underwater wireless optical communication system. In Optical Fiber Communication Conference (OFC) 1-3 (2019).

9. Wang, J., Lu, C., Li, S. \& Xu, Z. 100 m/500 Mbps underwater optical wireless communication using an NRZ-OOK modulated 520 nm laser diode. Opt. Express 27, 12171-12181 (2019).

10. Zhang, L. et al. Experimental demonstration of a two-path parallel scheme for m-QAM-OFDM transmission through a turbulentair-water channel in optical wireless communications. Opt. Express 27, 6672-6688 (2019).

11. Lu, H. H. et al. An 8 m/9.6 Gbps underwater wireless optical communication system. IEEE Photonics J. 8, 7906107 (2016).

12. Tsai, W. S. et al. $500 \mathrm{~Gb} / \mathrm{s}$ PAM4 FSO-UWOC convergent system with a R/G/B five-wavelength polarization-multiplexing scheme. IEEE Access 8, 16913-16821 (2020).

13. Tsai, W. S. et al. $256 \mathrm{~Gb} / \mathrm{s}$ four-channel SDM-based PAM4 FSO-UWOC convergent system. IEEE Photonics J. 11, 7902008 (2019).

14. Lin, T., Huang, N., Gong, C., Luo, J. \& Xu, Z. Preliminary characterization of coverage for water-to-air visible light communication through wavy water surface. IEEE Photonics J. 13, 7901013 (2021).

15. Sun, X. et al. On the realization of across wavy water-air-interface diffuse-line-of-sight communication based on an ultraviolet emitter. Opt. Express 27, 19635-19649 (2019).

16. Li, C. Y. et al. $50 \mathrm{~Gb} / \mathrm{s}$ PAM4 underwater wireless optical communication systems across the water-air-water interface (Invited). Chin. Opt. Lett. 17, 100004 (2019).

17. Li, C. Y. et al. A flexible bidirectional fiber-FSO-5G wireless convergent system. IEEE/OSA J. Light. Technol. 39, 1296-1305 (2021).

18. Yeh, C. H. et al. Utilizing single lightwave for delivering baseband/FSO/MMW traffics simultaneously in PON architecture. IEEE Access 7, 138927-138931 (2019).

19. Tsai, W. S., Lu, H. H., Wu, H. W., Su, C. W. \& Huang, Y. C.,. A 30 Gb/s PAM4 underwater wireless laser transmission system with optical beam reducer/expander. Sci. Rep. 9, 8605 (2019).

20. Chou, H. H. \& Huang, W. T. Asymmetrical bidirectional optical wireless communication system based on a transmissive 1D LCSLM for NG-PON2. Opt. Lett. 45, 4543-4546 (2020).

21. Harriman, J., Serati, S. \& Stockley, J. Comparison of transmissive and reflective spatial light modulators for optical manipulation applications. In Proceedings SPIE. 59302D-1-59302D-10 (2005).

22. Ijaz, M., Ghassemlooy, Z., Rajbhandari, S., Minh, H. L., Perez, J. \& Gholami, A. Comparison of $830 \mathrm{~nm}$ and $1550 \mathrm{~nm}$ based free space optical communications link under controlled fog conditions. In IEEE, IET International Symposium on Communication Systems, Networks and Digital Signal Processing 1-5 (2012).

23. Kim, I. I., McArthur, B. \& Korevaar, E. Comparison of laser beam propagation at $785 \mathrm{~nm}$ and $1550 \mathrm{~nm}$ in fog and haze for optical wireless communications. Proc. SPIE. 4214, 26-37 (2001).

24. Wang, J. et al. Underwater wireless optical communication system using a 16-QAM modulated 450-nm laser diode based on an FPGA. Appl. Opt. 58, 4553-4559 (2019).

25. Wu, T. C., Chi, Y. C., Wang, H. Y., Tsai, C. T. \& Lin, G. R. Blue laser diode enables underwater communication at 12.4 Gbps. Sci. Rep. 7, 40480 (2017).

26. Li, C. Y. et al. A $5 \mathrm{~m} / 25$ Gbps underwater wireless optical communication system. IEEE Photonics J. 10, 7904809 (2018).

27. Xu, J. et al. Underwater wireless transmission of high-speed QAM-OFDM signals using a compact red-light laser. Opt. Express 24, 8097-8109 (2016).

28. Zhang, C., Wei, H., Liu, Z. \& Fu, X. Characteristic ocean flow visualization using Helmholtz decomposition. IEEE Kobe TechnoOceans. 1-4 (2018).

29. Shen, Y. et al. Flow velocity and temperature measuring in large scale wave-current flume by coastal acoustic tomography. IEEE Kobe Techno-Oceans. 1-5 (2018).

30. Lee, I. E., Guo, Y., Ng, T. K., Park, K. H., Alouini, M. S. \& Ooi, B. S. Bandwidth enhancement of wireless optical communication link using a near-infrared laser over turbid underwater channel. In Conference on Lasers and Electro-Optics Pacific Rim (CLEO-PR). (2017).

31. Pittol, M., Tomacheski, D., Simões, D. N., Ribeiro, V. F. \& Santana, R. M. C. Evaluation of $\operatorname{commercial~} \mathrm{Mg}(\mathrm{OH})_{2}, \mathrm{Al}(\mathrm{OH})_{3}$ and $\mathrm{TiO}_{2}$ as antimicrobial additives in thermoplastic elastomers. Plast. Rubber Compos. 46, 223-230 (2017).

32. Fletcher, A. S., Hamilton, S. A. \& Moores, J. D. Undersea laser communication with narrow beams. IEEE Commun. 53, 49-55 (2015).

33. Oubei, H. M. et al. Performance evaluation of underwater wireless optical communications links in the presence of different air bubble populations. IEEE Photonics J. 9, 7903009 (2017).

34. Cochenour, B. M., Mullen, L. J. \& Laux, A. E. Characterization of the beam-spread function for underwater wireless optical communications links. IEEE J. Oceanic Eng. 33, 513-521 (2008).

35. Tsai, W. S. et al. A 50-m/320-Gb/s DWDM FSO communication with afocal scheme. IEEE Photonics J. 8, 7904007 (2016).

36. Zhao, X. et al. Novel cascaded injection-locked $1.55-\mu \mathrm{m}$ VCSELs with $66 \mathrm{GHz}$ modulation bandwidth. Opt. Express 15, 1481014816 (2007).

37. Lau, E. K. \& Wu, M. C. Amplitude and frequency modulation of the master laser in injection-locked laser systems. In IEEE International Topical Meeting on Microwave Photonics (MWP) MC-29, 142-145 (2004). 


\section{Acknowledgements}

This work was funded in part by Qualcomm through a Taiwan University Research Collaboration Project (NAT457595), and in part by National Taipei University of Technology-National Taipei University Research Collaboration Project (USTP-NTUT-NTPU-110-01).

\section{Author contributions}

H.-H.L., C.-Y.L., and X.-H.H. contributed to the experiment design. P.-S.C., Y.-T.C., Y.-Y.L., C.-X.L. and T.K. contributed to the experimental construction and measurement. H.-H.L., C.-Y.L., and X.-H.H. contributed to the data analysis. C.-Y.L., X.-H.H., P.-S.C., and Y.-T.C. contributed to the manuscript writing.

\section{Competing interests}

The authors declare no competing interests.

\section{Additional information}

Correspondence and requests for materials should be addressed to H.-H.L.

Reprints and permissions information is available at www.nature.com/reprints.

Publisher's note Springer Nature remains neutral with regard to jurisdictional claims in published maps and institutional affiliations.

(c) (i) Open Access This article is licensed under a Creative Commons Attribution 4.0 International License, which permits use, sharing, adaptation, distribution and reproduction in any medium or format, as long as you give appropriate credit to the original author(s) and the source, provide a link to the Creative Commons licence, and indicate if changes were made. The images or other third party material in this article are included in the article's Creative Commons licence, unless indicated otherwise in a credit line to the material. If material is not included in the article's Creative Commons licence and your intended use is not permitted by statutory regulation or exceeds the permitted use, you will need to obtain permission directly from the copyright holder. To view a copy of this licence, visit http://creativecommons.org/licenses/by/4.0/.

(C) The Author(s) 2021 